\title{
Ciudadanía, votos y armas. Elección de diputados en los llanos venezolanos y neogranadinos para el Congreso General de Colombia: 1820-1821
}

Citizenship, votes and weapons. Election of deputies in the Venezuelan and Neogranadian plains for the General Congress of Colombia: 1820-1821

Ángel Rafael Almarza Villalobos

Palabras clave

Resumen

\section{Abstract}

Keywords

Instituto de Investigaciones Históricas, Universidad Michoacana de San Nicolás de Hidalgo, Morelia, Michoacán Correo electrónico: almarzavillalobos@gmail.com

Doctor en Historia por la Universidad Nacional Autónoma de México. Investigador del Instituto de Investigaciones Históricas, Universidad Michoacana de San Nicolás de Hidalgo. Autor del libro Los inicios del gobierno representativo en la República de Colombia, 1818-1821.

Representación política, prácticas electorales, gobierno representativo, elecciones

Las elecciones son un medio para la comprensión de la cultura política de la República de Gran Colombia. El presente artículo analiza los comicios realizados en las provincias de Barinas y Casanare entre agosto de 1820 y octubre de 1821 para elegir a los representantes que asistirían al Congreso General de Colombia a celebrarse en Cúcuta. En comparación con ensayos previos, la experiencia y resultados obtenidos de estos comicios brindaron al sistema representativo colombiano la posibilidad de convertirse en un proyecto viable que duraría una década.

Elections are a means to understand the political culture of the Republic of Gran Colombia. This article analyzes the elections held in the provinces of Barinas and Casanare in August 1820 and October 1821, to elect the representatives who would attend the General Congress of Colombia to be held in Cúcuta. In comparison with previous elections, the experience and results obtained from this process offered the Colombian representative system the possibility of becoming a viable project that would last a decade.

Political representation, electoral practices, representative government, elections

Recibido/Received

Aprobado/Approved
24 de abril de 2017 10 de abril de 2018 


\section{Ciudadanía, votos y armas. Elección de diputados en los llanos venezolanos y neogranadinos para el Congreso General de Colombia: $1820-1821$}

Ángel Rafael Almarza Villalobos

\section{Preámbulo}

El 1 de enero de 1820 ocurrió un suceso que inclinó definitivamente la balanza de la guerra de independencia a favor del Ejército Libertador, y benefició con ello el establecimiento y consolidación del sistema representativo en la naciente República de Colombia. El acontecimiento al que hago referencia se llama Trienio liberal (1820-1823), el cual inició con el pronunciamiento del teniente coronel Rafael de Riego, responsable de apoyar con hombres y suministros las desgastadas fuerzas militares de Pablo Morillo, quien se encontraba desde 1815 al frente del Ejército Expedicionario de Costa Firme.

El 20 de marzo de 1820, Fernando viı cumplió con las principales exigencias de los liberales españoles: jurar y respetar la constitución de 1812 y la convocatoria inmediata a Cortes Generales como garantes de la soberanía nacional. De esta manera se buscaba el restablecimiento de las instituciones constitucionales y de sus autoridades en ambos lados del Atlántico. Es así como en España comenzó un período de cambio de dirección política respecto a las posesiones ultramarinas, específicamente en las llamadas insurgentes. En síntesis, fueron medidas orientadas a evitar la desintegración del imperio español en América por medio de sutiles reformas jurídicas cuyo propósito era contener las aspiraciones de participación y representación política de las élites inconformes desde 1810.

En este contexto, convocaron rápidamente a los americanos a enviar representantes para las nuevas cortes, decretaron el cese inmediato de hostilidades y giraron instrucciones para la búsqueda de soluciones pacíficas al conflicto. Nada más alejado de la realidad, ya que sólo se trató de un optimismo de los 
liberales españoles que desconocían, en primer lugar, los acontecimientos americanos de la última década; y en segundo término, más allá de reformas constitucionales puntuales, no estaban dispuestos a cambiar la forma de relacionarse con los dominios americanos. Para los políticos y militares insurgentes la independencia absoluta no era negociable.

Efectivamente, al poco tiempo se iniciaron las negociaciones entre los comisionados del gobierno español y las autoridades republicanas para suspender hostilidades y avanzar en la búsqueda de una solución pacífica al conflicto armado de casi una década de duración. Los resultados de estas intensas jornadas terminaron con éxito el 25 de noviembre de ese mismo año, 1820, con la firma del Tratado de Armisticio y el día siguiente con el de Regularización de la Guerra, ambos refrendados en la población venezolana de Santa Ana de Trujillo por el jefe de las Fuerzas Armadas de España en Venezuela y del Nuevo Reino de Granada Pablo Morillo, y por el general en jefe del Ejército Libertador y presidente de la República de Colombia Simón Bolívar. Estos compromisos constituyeron el reconocimiento de dos naciones beligerantes que negociaban las condiciones del enfrentamiento bélico.

En cuanto a la nación colombiana, el segundo Congreso de Venezuela reunido en la ciudad de Angostura sancionó la Ley Fundamental de Colombia el 17 de diciembre de 1819. De acuerdo a su contenido, a partir de ese momento se constituyó la República de Colombia integrada por los antiguos territorios de la Capitanía General de Venezuela y el Virreinato del Nuevo Reino de Granada, quedando dividida en tres departamentos: Venezuela, Quito y Cundinamarca. ${ }^{1}$ En ese momento quedó claro que la instancia encargada de formalizar el ordenamiento y funcionamiento político de la nueva nación sería el Congreso Constituyente de Colombia, el cual se reuniría en enero de 1821 en la Villa del Rosario de Cúcuta.

\footnotetext{
${ }^{1}$ Estaba contemplado tanto en la mencionada ley como en la constitución de la República de Colombia de 1821, que el territorio colombiano estaría dividido en departamentos, provincias, cantones y parroquias; mientras que en la constitución de la República de Venezuela de 1819 , la provincia estaría dividida solo en departamentos y parroquias. Es importante advertir que no se trata de una equivocación sino de la convivencia de ambas legislaciones -la Ley Fundamental y la constitución venezolana-, cuyos términos se manifestaron en diferentes oportunidades durante el proceso electoral en estudio.
} 
Así, en medio de intensas campañas militares y mientras se negociaban los términos de los tratados antes mencionados, se realizaron entre el 7 de agosto de 1820 y el 6 de octubre de 1821 en las provincias venezolanas y neogranadinas que se encontraban bajo el control del Ejército Libertador, las elecciones para la designación de los diputados que los representarían en el primer congreso colombiano. Al mismo tiempo, en los territorios que permanecieron fieles a la monarquía, se juró la constitución gaditana y se realizaron elecciones para diputados a cortes generales así como para los ayuntamientos constitucionales y diputaciones provinciales. La coexistencia de estos dos proyectos incompatibles se reflejó en las ricas y polémicas discusiones que se dieron en torno al sistema representativo, publicadas muchas de ellas en la prensa.

En definitiva, y luego de presentar esta breve síntesis del contexto político y militar, es importante mencionar que el presente artículo tiene como objetivo general estudiar los procesos electorales -en su nivel: parroquial y provincial; y en sus espacios: civil y militar-, que se realizaron específicamente en la provincia llanera de Barinas para la selección de sus representantes para el Congreso General de Colombia de 1821. Debo destacar que debido a la escasez de datos precisos de las elecciones parroquiales, incorporé en el análisis de manera auxiliar los comicios provinciales del Casanare. Si lo comparamos con ensayos representativos previos, ${ }^{2}$ la experiencia práctica y resultados obtenidos de estos comicios le brindaron la posibilidad al sistema representativo colombiano de convertirse en un proyecto viable que duraría una década, en donde la partici-

${ }^{2}$ Los autores que han abordado el problema de la representación política concuerdan en afirmar el impacto y trascendencia que tuvieron los primeros procesos electorales americanos iniciados desde 1809, y en particular por el doceañismo gaditano y las experiencias electorales insurgentes, en el posterior establecimiento de los gobiernos representativos en Hispanoamérica. Para el caso colombiano podría destacar los trabajos realizados por Armando Martínez Garnica (2003, 2004 y 2007) y el realizado por Guillermo Sosa Abella (2006). Para el venezolano el tema de la representación política y los procesos electorales han sido abordados inicialmente en atención a la participación del elemento militar durante los años iniciales del proceso de independencia. Sobre este particular destaca el trabajo de Irwin (2004) y Hébrard (2012). Más cercanos a la temática ciudadana encontramos los trabajos de Quintero (2006), Leal Curiel (2011) y Almarza V. (2007, 2011, 2012, 2012 y 2015). Sería interesante realizar una comparación con otras experiencias electorales para el conjunto de Tierra Firme, tanto las monárquicas como las insurgentes. 
pación ciudadana por medio de la elección de sus diputados fue el eje central de su gobierno y de su nueva forma de hacer política. En consecuencia, podría destacar que se trató de un esfuerzo político y logístico sin precedente: solventar las dificultades para realizar los comicios demuestra que existió una sólida voluntad, tanto de las autoridades como de la ciudadanía colombiana. ${ }^{3}$

Concretamente, para este artículo analicé las prácticas políticas en sus diversas dimensiones, considerando de manera específica los espacios vinculados con el proceso comicial y sus implicaciones en la cambiante dinámica política, social y militar de los ciudadanos de la naciente República de Colombia en el bienio de 1820 y 1821, pero de manera particular, me concentré en la región llanera venezolana y en menor medida en la neogranadina, constituidas en la división político-administrativa de la época por las provincias de Barinas y Casanare respectivamente. Su singularidad radica en que en ella se concentraba -sin menospreciar la disminuida participación civil-, el mayor contingente del Ejército Libertador y de la Legión Británica, convirtiendo las elecciones en un evento de particular trascendencia para comprender la cultura política del momento. ${ }^{4}$

Bajo esta perspectiva fue fundamental formularme las siguientes interrogantes: ¿cómo se desarrolló el proceso electoral del Congreso General de Colombia? ¿Se cumplió con la normativa vigente o existieron discrepancias? ¿Qué peculiaridades se evidenciaron en los comicios al ser el elemento militar el principal protagonista? Éstas y otras incógnitas me ayudaron a entender la trascendencia que adquirió para la vida política de los colombianos la convocatoria, reglamento y elección de diputados del congreso de Cúcuta, y con ello descartar la interpretación que caracterizó las elecciones como un proceso sin

${ }^{3}$ Un acercamiento a este problema lo desarrollé en mi tesis doctoral: Los inicios del gobierno representativo en la República de Colombia (2015). Durante dos años (2016-2017) conté con el apoyo de la Coordinación de la Investigación Científica de la Universidad Michoacana de San Nicolás de Hidalgo, para seguir desarrollando esta línea de investigación con el proyecto: Representación política y prácticas electorales. El caso de Colombia y el Río de la Plata, 18191823.

4 Entiendo por cultura política al conjunto de símbolos, ideas, actitudes, normas y creencias compartidas por los miembros de una determinada unidad social que dan sentido a la vida política de una comunidad política. Bobbio, Matteucci y Pasquino (2008, t. I, p. 415-417). 
alteraciones ni contradicciones, marcadas por el predominio de los dos líderes políticos y militares más influyentes del momento: Simón Bolívar y Francisco de Paula Santander, como reflejo de una rivalidad latente entre los venezolanos y neogranadinos que llevará a la disolución de la experiencia colombiana en 1830 y 1831 . El desconocimiento de los inicios de la representación política en Tierra Firme explica en buena medida el protagonismo otorgado a los caudillos, y más a los llamados héroes nacionales.

En ese sentido, las prácticas electorales representan una valiosa fuente para el estudio, análisis y comprensión de la cultura política en los inicios del establecimiento del gobierno representativo colombiano por diversas razones. La primera está vinculada al tema de la movilización ciudadana antes, durante y después de las jornadas comiciales, ya que son los encargados de la organización del evento. El interés -por su novedad, significación y alcance- que despertó en la población en general, así como la participación de la ciudadanía en el mismo acto electoral en sus dos niveles (parroquiales y/o provinciales) y en los dos espacios contemplados en la legislación (civil y militar), manifiesta una marcada e interesante politización de la sociedad del momento. La segunda razón está relacionada con el poder que adquirió el voto para acercar a la ciudadanía a la toma de decisiones políticas trascendentales, y como mecanismo idóneo de legitimación del régimen representativo colombiano. Aunque no estaban contempladas las candidaturas, el mecanismo de elección inevitablemente reafirmó la idea de competitividad para acceder a cargos gubernamentales, lo que motivó que ciertos liderazgos o grupos de interés buscaran el favor ciudadano por medio del voto. La tercera y última razón es que la movilización ciudadana, la participación política y el ejercicio del voto transformaron de alguna manera las relaciones de poder, dando sentido a dinámicas y prácticas enmarcadas en el sistema representativo colombiano de principios de la década de 1820.

Para una mejor percepción del espacio territorial al que hago referencia, dejo a continuación un detalle del mapa que representa la división política del Virreinato de Santafé en 1810, tomado del Atlas geográfico e histórico de la República de Colombia de 1890. Los Llanos son una región que actualmente se encuentra repartida entre Colombia y Venezuela en la cuenta del río Orinoco. 


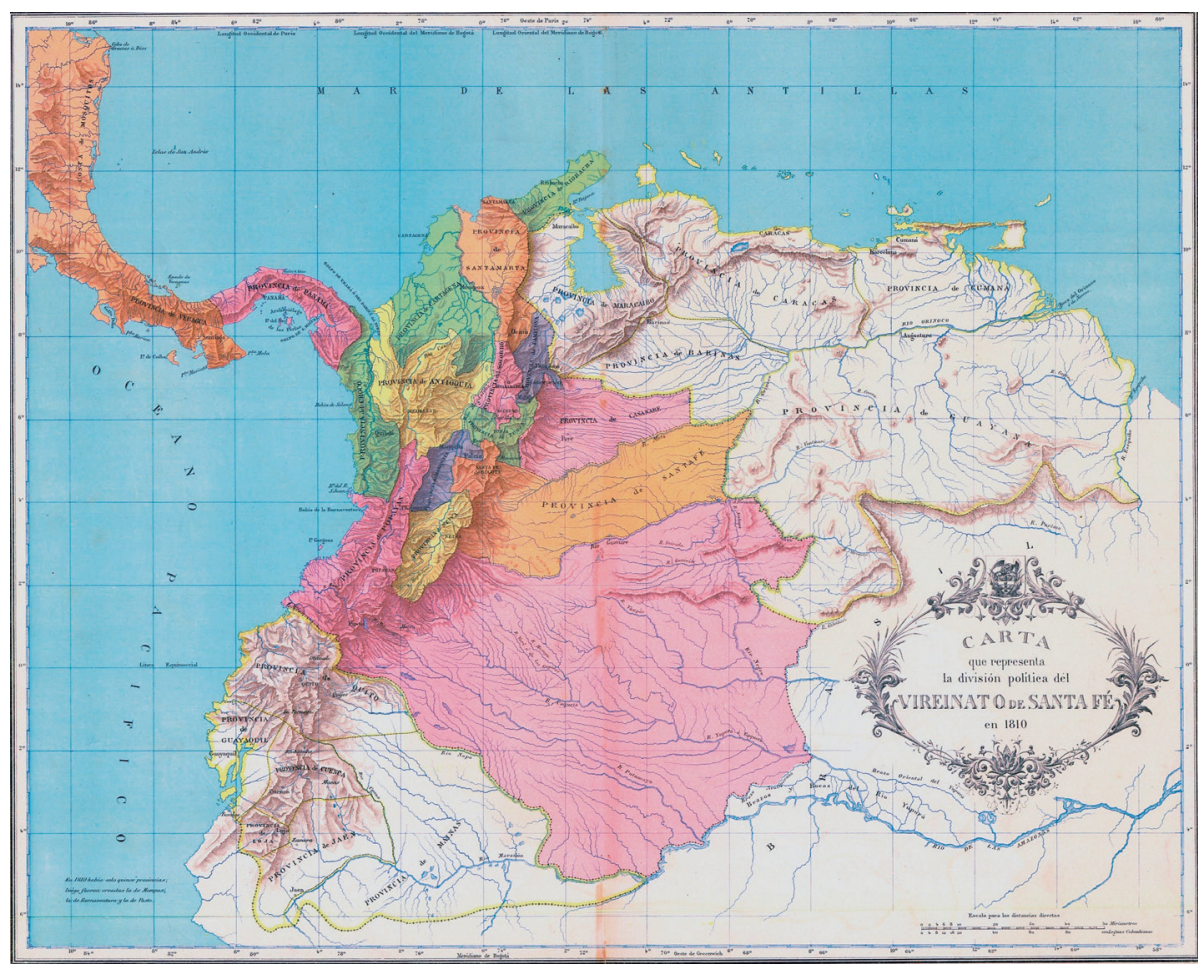

Mapa 1. Detalle de la carta que representa la división política del virreinato de Santa Fe en 1810. Tomado de Atlas geográfico e histórico de la República de Colombia (1890)

\section{Convocatoria y reglamento al Congreso General de Colombia}

Siguiendo con lo establecido en la Ley Fundamental de la República de Colombia, los diputados de Angostura aprobaron el 17 de enero de 1820, la convocatoria al primer congreso de Colombia y sancionaron el reglamento que normaría el proceso electoral para la selección de los diputados. ${ }^{5}$ La situación de la guerra determinó que se mantuvieran en la legislación comicial elementos de la anterior

5 "La convocatoria para el próximo congreso general de la República de Colombia" estaba integrada por dos apartados, "A los habitantes de la nueva República de Colombia” y el "Reglamento para las elecciones de los diputados que han deformar el Congreso General de Colombia en la Villa del Rosario de Cúcuta el 1 de enero de 1821, conforme a la Ley Fundamental de la República”. Se publicaron en el Correo del Orinoco, n. 51, 5 de febrero de 1820. 
convocatoria y el reglamento de 1818; no obstante, la ampliación del espacio geográfico y poblacional así como las irregularidades que se presentaron, exhortaron a los parlamentarios a plantear reformas en la nueva normativa como la implementación de las elecciones de segundo grado y mayores restricciones al ejercicio ciudadano. Sin embargo, a pesar de las limitaciones e inconvenientes, la elección fue considerada como uno de los principios fundacionales de la legitimidad política e institucional de la joven república colombiana.

En la alocución que antecede al reglamento titulado A los habitantes de la nueva República de Colombia, los diputados insistieron en los mismos argumentos de procesos eleccionarios anteriores para justificar de esta manera la importancia del establecimiento de un gobierno representativo en descrédito del monárquico: "Ya no dependéis de virreyes, ministros y gobernadores nombrados sin vuestro consentimiento." Ni tampoco será "la voluntad de un déspota la suprema ley de vuestros derechos, de vuestras propiedades y vida." En cambio, la dirección del gobierno y la toma de decisiones sería "la obra de vuestras manos, de vuestra razón y de vuestro discernimiento", al recobrar la libertad y la soberanía. ${ }^{6}$

El reglamento estableció que cada una de las provincias que integraban los antiguos territorios de la Capitanía General de Venezuela y del Virreinato del Nuevo Reino de Granada, independientemente de su número de habitantes, nombraría cinco diputados principales con sus respectivos suplentes en un proceso eleccionario de segundo grado, constituido por las asambleas parroquiales en un primer nivel de selección y en una segunda etapa compuesta por las asambleas provinciales. Estas se realizarían tanto en las provincias libres como en las instalaciones militares de los territorios que permanecían en situación extraordinaria como consecuencia de la guerra. La máxima autoridad civil o militar era responsable del proceso eleccionario. ${ }^{7}$

Los requisitos establecidos para el ejercicio del derecho al voto en las asambleas parroquiales privó de la participación política a la mayoría de la población masculina adulta de los territorios bajo el control republicano. Esta disminución

\footnotetext{
${ }^{6}$ Correo del Orinoco, n. 51, 5 de febrero de 1820.

7 "Reglamento para las elecciones de los diputados...", Correo del Orinoco, n. 51, 5 de febrero de 1820.
} 
fue consecuencia de al menos tres condiciones restrictivas, a saber: colombiano por nacimiento o nacionalización; casado o tener 21 años de edad; y ser propietario de bienes raíces valorados en al menos 500 pesos o en su defecto, ser profesional o militar. Para ser seleccionado como elector parroquial, los requisitos censitarios fueron aún mayores, ya que se debía ser propietario de bienes raíces valorados en más de 1000 pesos o una renta superior a los 500 pesos anuales, y residir en la parroquia donde se reunirían, caso contrario de los diputados provinciales quienes podían "ser escogidos entre todos los ciudadanos de la República, estén o no avecinados en las provincias o los departamentos de los electores". ${ }^{8}$ En esta etapa se consideró la participación de los extranjeros que habían colaborado en la guerra de independencia, así como los civiles propietarios y letrados que manifestaron su intención de establecerse en el territorio. No podían participar los criminales, deudores, locos, furiosos o dementes, o quienes hubieran estado vinculados a delitos electorales.

Estas asambleas parroquiales seleccionarían en votación pública y por mayoría simple a quince electores que participarían en las asambleas provinciales. En caso de igualdad de votos se admitió la práctica del sorteo. Según el reglamento, las asambleas parroquiales se reunirían tanto en instalaciones militares como en pueblos, villas y ciudades que se encontraran bajo el control del Ejército Libertador, y serían congregadas y presididas por su máxima autoridad civil o militar. ${ }^{9}$

En una segunda etapa del proceso, los quince representantes electos en las asambleas parroquiales se reunirían en las capitales de provincias o destacamentos militares para conformar las asambleas provinciales, las cuales tendrían como propósito la selección por votación pública y por mayoría absoluta de cinco diputados principales con sus respectivos suplentes, aunque éstos podían ser por mayoría simple. Los empates se resolverían a través del sorteo.

Para ser diputado del primer congreso de Colombia se debían cumplir con condiciones restrictivas que muy pocos ciudadanos podrían verificar, a saber: colombianos por nacimiento; mayores de 25 años; propietarios de bienes raíces

\footnotetext{
${ }^{8}$ Correo del Orinoco, n. 51, 5 de febrero de 1820.

9 Correo del Orinoco, n. 51, 5 de febrero de 1820.
} 
mayores de 5 ooo pesos o con una renta superior a 500 pesos anuales o ser profesional. ${ }^{10}$

En todo caso, la convocatoria y reglamento para la elección de diputados al primer congreso general de Colombia conservó su condición de sufragio censitario o restringido, basado en la dotación del derecho a voto sólo aquella parte de la población que cumpliera con características precisas. Los legisladores seleccionaron no sólo las reglas y procedimientos electorales más prácticos para la coyuntura de la guerra, sino también aquellos que le brindaron mayor probabilidad de obtener resultados satisfactorios para sus intereses, es decir, que fuesen seleccionados los hombres más virtuosos, representados en los propietarios, comerciantes y profesionales. La amplificación del derecho al voto se dio en función de la utilidad de los individuos, la cual ya no sólo correspondía exclusivamente a la propiedad, sino también a la de un oficio útil; es decir, ciudadanos que podían contribuir social y económicamente a la construcción de la República de Colombia que se rigió bajo un gobierno popular representativo.

Elecciones parroquiales en los llanos colombianos: el caso de la provincia de Barinas

El 28 de febrero de 1820 desde la ciudad de Angostura -capital provisional de la República de Colombia-, el vicepresidente del Departamento de Venezuela Juan Germán Roscio, envió una importante comunicación al comandante general de la provincia de Barinas, el general José Antonio Páez. La intención de la misiva era informarle sobre la realización en el territorio a su cargo de las elecciones para diputados principales y suplentes que asistirían al Congreso General de Colombia. En esa oportunidad, anexó tres ejemplares del Correo del Orinoco donde se encontraba la convocatoria y el reglamento de elecciones "a fin de que tomando las providencias convenientes; logre verificar este acto con la brevedad posible; y al mismo tiempo con la exactitud y acierto que merece

${ }^{10}$ Correo del Orinoco, n. 51, 5 de febrero de 1820. 
su importancia, cuyos nombrados me comunicará V. S. en su oportunidad”, le escribió Roscio. ${ }^{11}$

Todo parece indicar que el general llanero no le prestó la debida atención a la solicitud oficial y sólo se ocupó del asunto casi siete meses después. En efecto, le ordenó al general Miguel Guerrero, quien se desempeñaba para ese momento como gobernador político e intendente de la provincia de Barinas, realizar el proceso comicial lo más rápido posible: "Las ocupaciones que diariamente me rodean -decía Páez-y que sólo me permiten tiempo para atender los negocios de la guerra, me impiden poderme encargar del cumplimiento de la orden." Adjuntó a la comunicación los mismos documentos enviados por el vicepresidente venezolano, pero con una advertencia con respecto a la reglamentación, ya que consideraba que "no señala el modo de proceder a la elección, pero V. S. tal vez tendrá el modelo que allane esta dificultad". ${ }^{12}$ Aunque se dieron consultas puntuales sobre la normativa electoral, ninguna autoridad política y/o militar llegó a manifestar un problema de esta magnitud. En suma, los argumentos emitidos por Páez sobre sus ocupaciones militares en los llanos neogranadinos y venezolanos, sus dudas sobre cómo realizar el proceso electoral, además de los meses que separaban la convocatoria a la instalación del congreso, dilataron significativamente la jornada comicial en la región. ${ }^{13}$

${ }^{11}$ Juan Germán Roscio, Comunicación al general José Antonio Páez, Angostura, 28 de febrero de 1820, en Archivo General de la Nación de Colombia (en adelante AGNC), República, Fondo Congreso, leg. 24, rollo 23, f. 276.

${ }^{12}$ José Antonio Páez, Comunicación al general Miguel Guerrero, Achaguas, 12 de septiembre de 1820, en AGNC, Sección República, Fondo Congreso, leg. 24, rollo 23, f. 278.

${ }^{13}$ Cuando Simón Bolívar inició la Campaña Libertadora del Nuevo Reino de Granada en los primeros meses de 1819, al general José Antonio Páez le correspondió tomar acciones de seguridad y reserva estratégica en los llanos venezolanos y neogranadinos y así evitar un posible ataque de Pablo Morillo a las fuerzas militares patriotas. Esa situación se mantuvo hasta finales de 1820. Esta información coincide con el relato de los acontecimientos que se encuentran recopilados en la Autobiografía que el general llanero publicó en Nueva York en 1869: "Casi todo el año 20 se pasó en reuniry disciplinar reclutas, empotrerar caballos, coger y castrar todos, y poderlos en dehesa para tener reses cuando el ejército abriera la campaña, y en enviar armas para la Nueva Granada. Sin embargo de nuestra inacción en aquella época, el ejército de Apure era una amenaza permanente contra las fuerzas realistas de Venezuela, para impedir su unión con las que existían en la Nueva Granada”. Páez (1888, t. I, p. 243). 
A los dos días de haber recibido la misiva, el general Guerrero convocó a los "vecinos que se hallan entre esta población [Achaguas] y sus recintos por medio de un bando [...] para que se presenten dentro del término de ochos días contados desde hoy a dar sus votos", en este caso para la selección de los quince electores parroquiales, primera fase del proceso. Ese mismo 14 de septiembre de 1820 envió comisiones a los departamentos libres de la provincia de Barinas para que realizaran de manera expedita el mismo acto electoral. ${ }^{14}$ En el mapa 2 destaqué las poblaciones que participaron en el proceso eleccionario de 1820; el río Apure -delimitado con una línea gruesa roja-, divide el territorio ocupado por los ejércitos realistas ubicados al norte, y por el Ejército Libertador al sur. Desde los inicios de la guerra de independencia en 1811, el territorio de los llanos venezolanos se encontraba bajo una considerable tensión militar entre los bandos en pugnas, situación que se agudizó con el paso de los años. Esta situación es otra de las particularidades que convirtieron esta elección en un caso excepcional y digno de estudio.

De esta manera, entre el 15 y el 30 de octubre de ese año, y con la entusiasta participación de 173 ciudadanos -de los cuales 109 eran militares y 64 civiles-, se realizó en el pueblo de Achaguas el proceso para el nombramiento de los electores parroquiales. Estos últimos serían los responsables de seleccionar a los cinco diputados principales y sus suplentes, los cuales representarían a la provincia de Barinas en el Congreso General de Colombia. ${ }^{15}$ El procedimiento para emitir el voto era el siguiente: en presencia de las autoridades del pueblo cada uno de los sufragantes pronunciaba su nombre, oficio, naturaleza, vecindad, estado y edad; si cumplía con los requisitos para ejercer su derecho ciudadano pronunciaba en voz alta los nombres de los quince electores parroquiales de su preferencia. Para terminar el acto -y de esta manera legitimaba su decisión-, el ciudadano debía firmar el cuaderno electoral, y en caso de no saber, bastaba una cruz o la rúbrica de alguien de su confianza. ${ }^{16}$ Conviene subrayar

${ }_{14}$ Nombramiento de electores parroquiales del departamento de Achaguas, Achaguas, 14 al 30 de septiembre de 1820, AGNC, República, Fondo Congreso, leg. 24, rollo 23, f. 280-304 v.

15 Nombramiento de electores parroquiales del departamento de Achaguas, Achaguas, 14 al 30 de septiembre de 1820, AGNC, República, Fondo Congreso, leg. 24, rollo 23, f. 280-304 v.

${ }^{16}$ Aunque la firma no significaba necesariamente que supiera leer y escribir, podría ser un indicativo y así lo utilicé en el análisis de la documentación electoral. Igualmente podría ser 


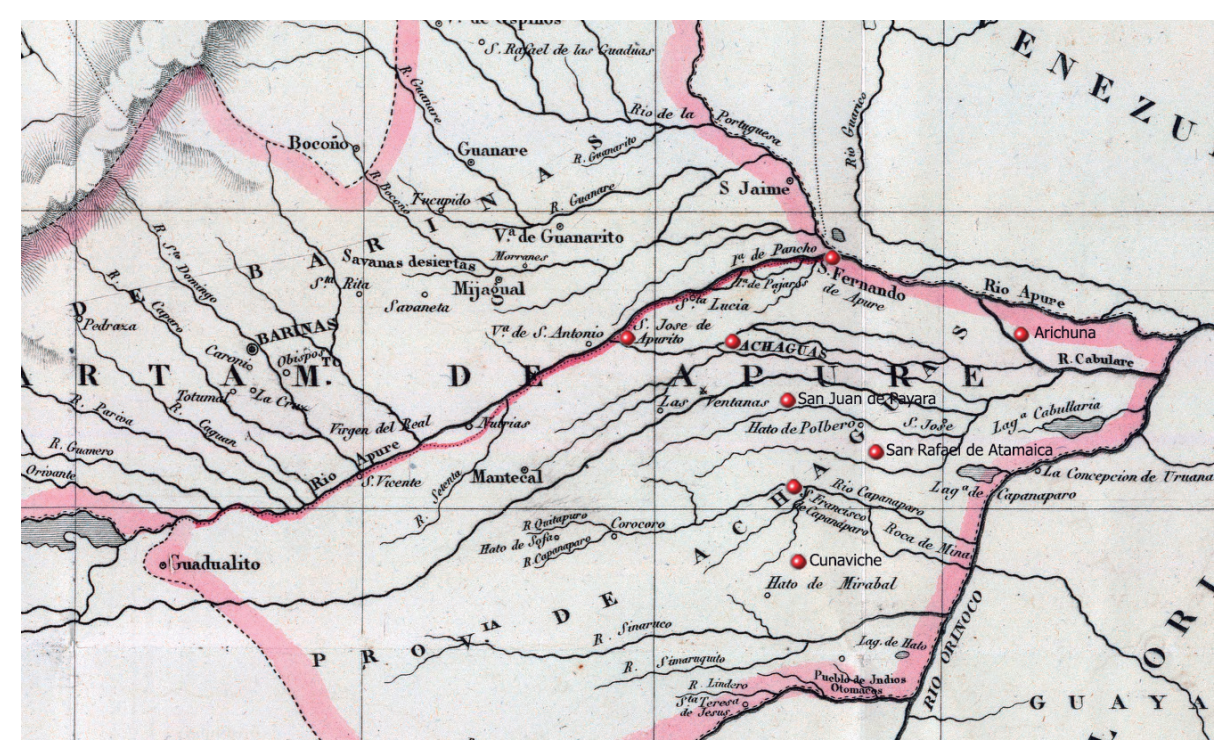

Mapa 2. Poblaciones de la provincia de Barinas que participaron en las elecciones parroquiales de 1820. Detalle tomado de la “Carta del Departamento de Apure”, Restrepo (1827)

que el poder de decisión de los funcionarios políticos y militares de calificar a los votantes sin seguir parámetros uniformes en la provincia de Barinas, sumado al carácter público de las elecciones, marcaron un proceso caracterizado por su complejidad, diversidad y aunque no fue generalizado, también de abuso de autoridad y atropello a la ciudadanía.

En su mayoría, los civiles que participaron eran oriundos de poblaciones colindantes al pueblo de Achaguas como San Fernando de Apure, Barinas, Calabozo o Guanare; algunos pocos nacieron en ciudades más distantes como Cumaná, Caracas o Maracaibo. Entre los votantes destacó la concurrencia de seis extranjeros provenientes de regiones como Escocia, Irlanda e Inglaterra, quienes formaron parte de la Legión Británica. A diferencia de los militares, la

subjetivo, pero consideré la caligrafía de la firma para valorar mejor este punto. Será a partir de la Constitución de la República de Colombia de 1821, cuando los congresistas establecerían la condición de saber leer y escribir para desempeñarse como sufragante parroquial. Esta medida sólo entraría en vigor a partir de 1840 para así darle tiempo a la implementación de un sistema educativo más incluyente que permitiera una mayor participación ciudadana. 
mayoría de los civiles estaban casados -42 de 64-, promediaban 39 años de edad y a excepción de 24 ciudadanos, el resto sabían firmar. ${ }^{17}$

Por su parte, los 109 ciudadanos en armas que participaron, integraban parte de las fuerzas militares más preparadas y especialmente leales al general José Antonio Páez, al encontrarse en la población de Achaguas el centro político y militar de la provincia de Barinas, núcleo del Ejército Libertador. En su mayoría eran oficiales de alto rango -87 de 109-, destacando dos generales, dos coroneles, doce tenientes coroneles, 36 capitanes y 25 tenientes. Esta situación atípica no se repitió en las elecciones parroquiales de otras poblaciones de la provincia ni de la República de Colombia, donde el proceso electoral se caracterizó en la masiva participación de los suboficiales y la tropa. Además de la concentración de la oficialidad en el poblado, la estricta selección de los votantes también ayudó a que se diera esta particularidad. Parte considerable de los participantes provenía de poblaciones pertenecientes a la provincia de Barinas y sus inmediaciones; otros nacieron en pueblos y ciudades más alejados como Cumaná, Barcelona, Margarita, Caracas, La Victoria, Maracay, Barquisimeto y Maracaibo, mientras que del lado del Nuevo Reino de Granada eran originarios de lugares como Ibagué, Popayán, Santa Fe, El Socorro y Tunja.

Asimismo, entre los militares que ejercieron su derecho ciudadano se encontraban 21 oficiales y un suboficial de la Legión Británica, a saber: dos tenientes coroneles, un mayor, doce capitanes, seis tenientes y un sargento (catorce ingleses, siete escoceses y un irlandés). En los cuadernos electorales destacan nombres como los del general José Antonio Páez, el general Miguel Guerrero, el jefe del estado mayor coronel Miguel Vázquez, el edecán de Páez el capitán inglés George Woodberry y el joven capitán de 24 años de edad Anacleto Clemente Bolívar, sobrino y edecán de Simón Bolívar. Eran solteros el 61\% de efectivos militares, quienes promediaban los 31 años de edad ( 8 menos que los civiles) y un $79 \%$ refrendaron la elección con su rúbrica en el cuaderno electoral. ${ }^{18}$

17 Nombramiento de electores parroquiales del departamento de Achaguas, Achaguas, 14 al 30 de septiembre de 1820, AGNC, República, Fondo Congreso, leg. 24, rollo 23, f. 280-304 v.

18 Nombramiento de electores parroquiales del departamento de Achaguas, Achaguas, 14 al 30 de septiembre de 1820, AGNC, República, Fondo Congreso, leg. 24, rollo 23, f. 280-304 v. 
Cabe mencionar que la Legión Británica fue el nombre que se le dio desde su llegada a Tierra Firme a las diversas unidades combatientes provenientes principalmente de Inglaterra, Escocia e Irlanda que participaron en la región septentrional de América del Sur durante las guerras de independencia. Esta idea de reclutar voluntarios sólo se concretó a partir de 1817 cuando Simón Bolívar nombró a Luis López Méndez como agente de la República de Venezuela en Londres, y a quien le encargó conseguir reclutas y armas. ${ }^{19}$ Aunque los datos no son precisos, se calcula que hasta finales de 1819 habrían partido de los puertos británicos poco más de 6800 voluntarios entre oficiales, soldados y unos cuantos civiles. ${ }^{20}$

En este caso, los militares de la Legión Británica que participaron en las elecciones de la provincia de Barinas de 1820, pertenecían a las expediciones comandadas por James Towars English y George Elsom. Las tropas dirigidas por el primero estaban integradas por unos 1200 voluntarios y desembarcaron en la isla de Margarita en abril de 1819; por su parte, las del segundo -con poco menos de la mitad de aventureros-, llegaron cuatro meses más tarde, divididos entre Margarita y Angostura, e inmediatamente conducidos a los llanos de Barinas. Parte de este cuerpo acompañó a Bolívar en la campaña militar que terminó con la liberación del Nuevo Reino de Granada a finales de 1819. Por su parte, los de English tomaron parte en la fallida campaña del oriente venezolano bajo las órdenes del general Rafael Urdaneta; posteriormente se trasladaron a los llanos barineses donde ambos grupos fueron organizados bajo una sola unidad: Cazadores Británicos al mando del general José Antonio Páez, quien por cierto, disfrutaba la presencia de los extranjeros. ${ }^{21}$ No dudo que esta cercanía influyera para que tuvieran una masiva participación en las elecciones parro-

19 La bibliografía sobre la Legión Británica y su participación en la guerra de independencia es amplia. Quiero destacar dos trabajos recientes: Brown (2010) y Mondolfi (2011).

${ }^{20}$ Los datos proporcionados son resultado de la investigación realizada por Brown (2010, p. 56-58). El destino de los aventureros de la Legión Británica fue diverso: un millar optó por regresar a su tierra sin haber usado un arma en Tierra Firme; casi 2000 murieron en campañas militares; unos 1500 fallecieron a consecuencia de enfermedades; unos 500 se establecieron en tierras colombianas, ecuatorianas y venezolanas al concluir la guerra; y unos 2 ooo combatieron y regresaron a Europa. Mondolfi (2011, p. 166).

${ }^{21}$ Brown (2010, p. 56-58). Son diversos los relatos que describen a Páez como una figura respetada por los llaneros, pero cercana y popular al mismo tiempo. Su jovialidad y condescen- 
quiales de la provincia de Barinas de 1820, ya que seguramente la mayoría de ellos no cumplía con uno de los requisitos establecidos en el reglamento electoral para su participación: haber manifestado su "intención de establecerse en la República, casándose con una colombiana, o trayendo su familia a Colombia”. ${ }^{22}$

Además de esta posible infracción a la legislación comicial, un estudio detallado del expediente me permitió determinar que en las elecciones parroquiales de Achaguas participaron al menos cinco individuos que no cumplían con el requisito mínimo de edad y estado, evidencia de otra irregularidad. Es un número considerablemente menor si lo comparamos con las asambleas realizadas en otras poblaciones de la provincia de Barinas, donde la selección de los votantes fue aún más arbitraria debido a que no existían parámetros precisos de calificación, con lo cual la opinión de las autoridades civiles y militares era determinante. ${ }^{23}$

Siguiendo con esta problemática, es importante mencionar que la experiencia electoral se vivió de manera diferente en las demás poblaciones de la provincia de Barinas pertenecientes al Departamento de San Fernando, específicamente en San Juan de Payara, San Fernando de Apure, Arichuna, San Rafael de Atamaica y Cunaviche, donde el general Miguel Guerrero anuló las votaciones y ordenó su repetición. No existió una justificación de la decisión del gobernador político e intendente de la provincia, en todo caso, por detalles muy específicos que encontré en el expediente electoral, pude inferir que esta decisión se debió al incumplimiento de la legislación comicial y a diversos inconvenientes presentados durante el proceso. A continuación presento cómo transcurrieron estas elecciones en los llanos venezolanos. ${ }^{24}$

dencia de su carácter fue lo que llamó más la atención de los legionarios británicos, además de su liderazgo en el campo militar. Mondolfi (2011, p. 158, 159).

${ }^{22}$ Artículo 3 "Reglamento para las elecciones de los diputados que han de formar el Congreso General de Colombia en la Villa del Rosario de Cúcuta el 1 de enero de 1821, conforme a la Ley Fundamental de la República”. Se publicó en el Correo del Orinoco, n. 51, 5 de febrero de 1820.

${ }^{23}$ Nombramiento de electores parroquiales del departamento de Achaguas, Achaguas, 14 al 30 de septiembre de 1820, AGNC, República, Fondo Congreso, leg. 24, rollo 23, f. 280-304 v.

24 El expediente relativo al proceso de estas poblaciones se encuentra en: Repetición del proceso para la selección de electores parroquiales en el Departamento de San Fernando, 
En una comunicación enviada al coronel Judas Tadeo Piñango -máxima autoridad política y militar del Departamento de San Fernando-, el general Guerrero le ordenó realizar un nuevo proceso para el nombramiento de electores parroquiales. La misiva firmada en Achaguas el 15 de septiembre de 1820, expresó la urgencia de su realización en respuesta a la orden del general Páez y el retraso que significó repetir el proceso electoral. Según los cálculos de Guerrero, debía estar concluido al "término de diez días contados desde mañana" pues así "importa al servicio de la República." Sus disposiciones fueron precisas: debían practicarse "conforme al reglamento" y "cuándo V. S. haya concluido las votaciones de todos los pueblos examinará privadamente quiénes son los quince electores que resultasen en el Departamento y deberá hacerlos venir de modo que estén aquí a más tardar el 26 [de octubre de 1820]." A pesar de la insistencia, las votaciones en el Departamento de San Fernando apenas concluyeron el 24 de octubre de $1820 .{ }^{25}$

Precisamente por estas últimas líneas de la comunicación, presumo que en las votaciones que se anularon se seleccionaron ciudadanos que no cumplían con las condiciones de elegibilidad para desempeñarse como electores parroquiales, tal como estaba establecido en el artículo 2 del reglamento electoral, a saber: ser vecinos de la provincia, propietarios o asalariados, profesionales o letrados; condiciones que difícilmente podía cumplir una decena de ciudadanos en las circunstancias de ese momento, y más aún en una provincia predominantemente rural alejada de los centros urbanos como Angostura, Cumaná, Mérida, Maracaibo, Valencia o Caracas. ${ }^{26}$

provincia de Barinas, septiembre y octubre 1820, AGNC, República, Fondo Congreso, leg. 24 , rollo 23 , f. 44-156 v.

${ }^{25}$ Miguel Guerrero, Comunicación al coronel Judas Tadeo Piñango relativa a la repetición del proceso electoral en el Departamento de San Fernando, Achaguas, 15 de septiembre de 1820, AGNC, República, Fondo Congreso, leg. 24, rollo 23, f. 44-45 bis.

${ }^{26}$ El artículo 2 del reglamento del 20 de enero de 1820 establecía: "Los cinco diputados de cada provincia serán nombrados por quince electores que además de las calidades requeridas por el articulo siguiente habrán de ser mayores de veinte y un años, vecinos de alguna de las parroquias del distrito donde han de juntarse para elegir diputados; poseedores de una propiedad raíz estimable en mil pesos, o de un empleo de quinientos pesos de renta anual, o usufructuarios de bienes que produzcan quinientos pesos anuales, o profesores de alguna ciencia o arte, o que tengan un grado científico." Correo del Orinoco, n. 51, 5 de febrero de 1820. 
La actividad no se realizó con la prontitud que el general Manuel Guerrero ordenó; organizar nuevamente un proceso en estas poblaciones requería un tiempo prudencial mayor a los diez días establecidos previamente. Así, bajo la dirección del coronel Judas Tadeo Piñango se realizó del 16 al 18 de octubre de 1820, el nombramiento de electores parroquiales en el pueblo de San Juan de Payara y sus inmediaciones. En total participaron 370 ciudadanos distribuidos entre 300 militares y 70 civiles, para una relación de $83 \%$ y $17 \%$ respectivamente. Gracias a la información contenida en las actas electorales logré analizar características de los votantes y conocer la dinámica de la jornada comicial, así como establecer algunos elementos particulares de la cultura política de esta región, a continuación una muestra de los datos obtenidos. ${ }^{27}$

En San Juan de Payara, por ejemplo, la mayoría de los civiles eran oriundos del mismo pueblo o de sus inmediaciones. Entre ellos destaca la participación de dos extranjeros, Pedro Pérez de 70 años de edad, originario de las Islas Canarias aunque tenía tiempo viviendo en esta población, y el irlandés Vicente Mulery, de 25 años de edad, quien se desempeñaba como cirujano de la Legión Británica. Estos datos, sumados a los de otras localidades de la provincia, evidencian que a pesar de la inestabilidad de la guerra, al menos la población civil llanera no sufrió migraciones significativas, como sí ocurrió en otras regiones del territorio venezolano y neogranadino. Sobre la actividad u oficio que ejercían fueron pocos quienes dieron esa información, o no fue plasmado en los cuadernos electorales; entre ellos resaltan ciudadanos vinculados con la vida política de Payara y sus alrededores: alcaldes, intendentes, administradores y gobernador de pueblo de indios; algunos eclesiásticos como presbítero, cura y sacristán; así como empleados del Ejército Libertador como contador de hospital, cirujanos y ayudante general; otros se presentaron como carpinteros, sastres u obreros. Casi el $80 \%$ de los hombres estaban casados y promediaban una edad de 43 años de edad y una proporción similar de quienes firmaron y quiénes no. ${ }^{28}$

${ }^{27}$ Nombramiento de electores parroquiales del pueblo de San Juan de Payara y sus inmediaciones, septiembre y octubre de 1820, AGNC, República, Fondo Congreso, leg. 24, rollo 23, f. 55-105 v.

${ }^{28}$ Nombramiento de electores parroquiales del pueblo de San Juan de Payara y sus inmediaciones, septiembre y octubre de 1820, AGNC, República, Fondo Congreso, leg. 24, rollo 23, f. 55-105 v. 
Por su parte, los 300 ciudadanos en armas que participaron en el nombramiento de electores parroquiales de San Juan de Payara, pertenecían en su mayoría al batallón Bravo de Apure del Ejército Libertador, acantonado para esos meses en esa población, aspecto que le dio características particulares con respecto a los civiles y a otros cuerpos castrenses establecidos en otras regiones de la provincia de Barinas. Esta fracción se encontraba al mando del general Pedro León Torres; destaca la presencia mayoritaria de la tropa de bajo rango como soldados (61\%), cabos (14\%) y sargentos (7\%), y en menor medida figuran los oficiales de mediano rango con dirección de tropas como los tenientes, capitanes y mayores (en total 10\%). ${ }^{29}$

$\mathrm{Al}$ pertenecer estos ciudadanos a un cuerpo como el batallón Bravo de Apure, los datos relativos al lugar de nacimiento que proveen los cuadernos electorales son interesantes para entender la dinámica de estas votaciones en el contexto de la guerra. Aunque una parte considerable de estas fuerzas era originaria de poblaciones de la provincia de Barinas o sus cercanías, muchos más provenían de rincones alejados de Venezuela como Angostura, Cumaná, Barcelona y Maturín al Sur y Oriente; Caracas, La Guaira, Maracay y Valencia en el Centro, y en el Occidente, Barquisimeto, Guanare y Maracaibo.

Pero lo más interesante es que un número significativo de militares nacieron en pueblos, villas y ciudades que pertenecían a las antiguas provincias que conformaban el Virreinato del Nuevo Reino de Granada, destacando entre las más importante Vélez y El Socorro; y en menor cuantía Villa del Rosario, Cúcuta, San Gil y Pamplona, poblaciones cercanas a las provincias de Mérida y Barinas. Otros pocos venían de pueblos del centro neogranadino como Zipaquirá, Santa $\mathrm{Fe}$, Bogotá, Villa de Leiva, Ortiz, Tunja y Chiquinquirá; o de la misma Cartagena, en la costa caribeña. Esta dispersión -con una proporción ligeramente mayor de militares venezolanos-, se debió principalmente a que el mencionado batallón formó parte de las fuerzas castrenses que participaron en la exitosa campaña de liberación del Nuevo Reino de Granada en agosto de 1819, misma que se trasladó posteriormente a los llanos venezolanos. En síntesis, los cuadernos

${ }^{29}$ Nombramiento de electores parroquiales del pueblo de San Juan de Payara y sus inmediaciones, septiembre y octubre de 1820, AGNC, República, Fondo Congreso, leg. 24, rollo 23 , f. 55-105 v. 
electorales dan cuenta de que los militares provenían de al menos 70 poblaciones distintas, incluyendo extranjeros de Cádiz (España), Saint Thomas (Caribe) y Guayaquil (Reino de Quito)..$^{30}$

Otra particularidad del sector militar es que en su mayoría eran hombres solteros -198 de 300-, menos de la tercera parte de ellos sabían firmar -75 de $300-$, y promediaban una edad de 26 años..$^{31}$ El promedio de edad significativamente más baja que el de los efectivos militares se debió a que casi un tercio de estos (96 individuos), tenían edades comprendidas entre los quince y 20 años, y siguiendo la normativa que regía el proceso electoral, de estos ciudadanos sólo podrían participar los que estuvieran casados; según los datos proporcionados por los cuadernos electorales, apenas seis cumplían con ese requisito. De esta manera, se violentó la legislación electoral que regulaba la actual elección.

El artículo 3 del reglamento estableció las condiciones que debía cumplir el ciudadano colombiano para participar en las asambleas primarias: "nacidos en el territorio de la república, domiciliados en cualquier parroquia, casados, 0 mayores de veinte y un años"; continúa la legislación electoral lo siguiente: "poseedores de una propiedad raíz de quinientos pesos de valor en cualquier parte de Colombia, o profesores de alguna ciencia o arte liberal, o mecánica con grado o aprobación pública; o militares naturales o extranjeros que hayan combatido por la república". ${ }^{32}$ Es posible que la confusión surgiera a partir de estas últimas líneas, y que el coronel Judas Tadeo Piñango considerara que la sola condición de militar era suficiente para la participación en esta primera etapa del proceso electoral, descartando la condición de la mayoría de edad. Ciertamente la legislación era ambigua en algunos apartados y este era uno de ellos. En todo caso, el proceso se realizó sin comentarios o críticas de las máximas autoridades de la provincia de Barinas, validando de esta manera las votaciones

${ }^{30}$ Nombramiento de electores parroquiales del pueblo de San Juan de Payara y sus inmediaciones, septiembre y octubre de 1820, AGNC, República, Fondo Congreso, leg. 24, rollo 23 , f. 55-105 v.

${ }^{31}$ Nombramiento de electores parroquiales del pueblo de San Juan de Payara y sus inmediaciones, septiembre y octubre de 1820, AGNC, República, Fondo Congreso, leg. 24, rollo 23 , f. 55-105 v.

32 Correo del Orinoco, n. 51, 5 de febrero de 1820. 
del pueblo de San Juan de Payara y sus inmediaciones, a pesar de las irregularidades reseñadas. Caso que se repetirá en otras localidades del territorio llanero venezolano.

Mientras tanto, la asamblea parroquial de los pueblos de San Rafael de Atamaica y Cunaviche realizó el proceso eleccionario entre el 18 y el 21 de octubre de 1820, con el capitán José Vicente Gaines a cargo de su organización. Participaron en total 42 ciudadanos originarios en su mayoría de los mismos pueblos o de localidades cercanas como San Fernando de Apure, Calabozo, El Sombrero, Guanare, San Carlos o San Jaime. Casi el 80\% eran hombres casados dedicados a la actividad agropecuaria, con una edad promedio de 44 años; una importante porción de ellos no firmaron su nombre en el cuaderno de votaciones por no saber hacerlo. En estas elecciones no se contabilizó la presencia de efectivos militares. ${ }^{33}$

Por otra parte, el pueblo de Arichuna practicó su proceso eleccionario el 19 de octubre de 1820 bajo la responsabilidad del teniente coronel Juan Lamas. Participaron en total 129 ciudadanos, de los cuales 106 eran militares y sólo 23 eran civiles; estos últimos era oriundos de poblaciones cercanas y se dedicaban a la agricultura, ganadería y la pesca. La mayoría eran hombres casados, promediaban 31 años de edad y pocos firmaron los cuadernos electorales. En una clara violación a la normativa electoral, en el proceso participaron cinco ciudadanos menores de 20 años que no estaban casados y como tal, no estaban facultados para ejercer el derecho al voto. Como en casos anteriores, no existió reclamo o impugnación por esta irregularidad. ${ }^{34}$

En el caso de los ciudadanos al servicio de las armas, existieron semejanzas al caso de las tropas establecidas en San Juan de Payara. Al formar parte del

33 La orden para la realización del proceso la emitió el coronel Judas Tadeo Piñango desde San Juan de Payara el 15 de octubre de 1820. Nombramiento de electores parroquiales de los pueblos de San Rafael de Atamaica y Cunaviche, del 18 al 21 de octubre de 1820, AGNC, República, Fondo Congreso, leg. 24, rollo 23, f. 107-116 v.

34 Igual que en el pueblo de San Rafael de Atamaica y Cunaviche, la orden para la realización del proceso la emitió el coronel Piñango el 15 de octubre de 1820. El expediente de estas votaciones se encuentra deteriorado e incompleto; procuré rescatar la mayor información posible. Nombramiento de electores parroquiales del pueblo de Arichuna, 19 de octubre de 1820, AGNC, República, Fondo Congreso, leg. 24, rollo 23, f. 122-124, 129, 138-138 bis, 140-150. 
Ejército Libertador -algunos pertenecían al Regimiento de dragones y otros al Batallón de granaderos-, el origen de sus integrantes es variopinto aunque la mayoría provenía de pueblos llaneros venezolanos o de regiones próximas al Nuevo Reino de Granada. Entre los oficiales extranjeros destaca un subteniente chileno de nombre Gregorio Alquisiro, y entre los soldados se hallaban dos españoles, dos ingleses y un quiteño. ${ }^{35}$ En su mayoría eran hombres solteros, promediaban unos 25 años de edad y pocos sabían firmar. Como en el caso del pueblo de Payara, en este proceso participaron 22 militares que no cumplían con la edad ni con el estado civil requeridos. Un ejemplo fue el soldado José Antonio Arratia, oriundo de San Sebastián de los Reyes, quien a sus catorce años de edad fue el votante más joven de la provincia de Barinas registrado en los cuadernos electorales. ${ }^{36}$ Nuevamente se violentó la normativa electoral sin que alguna autoridad civil o militar se manifestara al respecto.

A cuatro días de haberse realizado las elecciones en el pueblo de Arichuna, correspondió al mismo teniente coronel Juan Lamas organizar el proceso en San Fernando de Apure, población que tenía como principal actividad económica la ganadería. Las votaciones se efectuaron el 23 de octubre de 1820 y participó un total de 150 ciudadanos, 94 de ellos militares y 56 civiles. Al igual que en otros poblados de la provincia de Barinas, el origen de la población civil no varió significativamente, aunque se podrían destacar los pueblos de Calabozo, San Carlos, San Fernando de Apure y San José de Tiznados como los más notorios. En su mayoría, los votantes civiles estaban casados, promediaron una edad de 34 años y pocos escribieron sus nombres en los cuadernos electorales. En estas votaciones se violentó nuevamente el artículo 3 del reglamento, ya que participaron siete ciudadanos que no cumplían con la mayoría de edad ni estaban casados. Las autoridades políticas y militares no refutaron esta

35 La distribución por rango de los militares que participaron fue el siguiente: 17 oficiales (dos tenientes coroneles; un mayor; tres capitanes; tres tenientes y ocho subtenientes); 19 suboficiales (siete sargentos y doce cabos) y 70 soldados. Nombramiento de electores parroquiales del pueblo de Arichuna, 19 de octubre de 1820, AGNC, República, Fondo Congreso, leg. 24 , rollo 23 , f. $122-124 ; 129 ; 138-138$ bis; $140-150$.

${ }^{36}$ Nombramiento de electores parroquiales del pueblo de Arichuna, 19 de octubre de 1820, AGNC, República, Fondo Congreso, leg. 24, rollo 23, f. 122-124, 129, 138-138 bis, 140-150. 
irregularidad, misma que fue recurrente tal y como he reseñado en los anteriores procesos. ${ }^{37}$

$\mathrm{Al}$ igual que algunos casos estudiados, los militares que ejercieron su derecho ciudadano provenían de poblaciones cercanas como Barinas, Caicara, Calabozo, Guanare, Ortiz, San Carlos y el mismo San Fernando de Apure. Lo más destacado de estas votaciones fue la participación de 25 militares de la Legión Británica. Los irlandeses fueron mayoría con trece, seguidos por los ingleses con once y sólo uno de Escocia; y a excepción de un subteniente, cinco sargentos y tres cabos, el resto fueron soldados que en sus regiones se desempeñaban originalmente como labradores, carpinteros, zapateros u otros

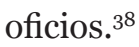

Los militares de más alto rango que ejercieron su voto fueron los tenientes coroneles Andrés Aguilera y Rafael Rodríguez; seguido por un capitán, cinco tenientes, un subteniente y tres alférez; los suboficiales suman 19 y la mayoría de los militares que participaron eran soldados. Las dos terceras partes eran solteros, y casi exclusivamente los oficiales y extranjeros fueron los únicos que pudieron firmar el cuaderno electoral. Al igual que el caso de los militares que participaron en los pueblos de Arichuna y San Juan de Payara, la edad promedio fue de 26 años, número bajo debido a que entre los suboficiales y soldados se

37 Nombramiento de electores parroquiales de San Fernando de Apure, San Fernando de Apure, 23 de octubre de 1820, AGNC, República, Fondo Congreso, leg. 24, rollo 23, f. 120, 121, $124-127,130-138,150-156$.

${ }^{38}$ Esta información es confirmada por un documento que reposa en el Archivo Histórico de Guayas, en Guayaquil, Ecuador [Actas, 1-6, Achaguas 1820]. Se trata de una lista de 319 aventureros que compilaron los oficiales de la Legión Británica en la población barinesa de Achaguas que data de finales de 1820. Del total de extranjeros, al menos 148 se describieron como jornaleros; la siguiente ocupación más popular era tejedor, seguido de zapateros, sastres, panaderos, músicos, carpinteros, encuadernadores, sastres, pintores, carniceros, sombrereros, mineros, contadores, comerciantes de sebo y velas, artesanos, jardineros, maquinistas, ebanistas, armeros, criados, entre otros. Brown (2010, p. 48-50). Estos datos sugieren que las expediciones no fueron exclusivamente empresas de carácter militar, y que tanto los líderes insurgentes como los reclutados europeos, vieron esta posibilidad como una emigración al continente americano en la búsqueda de mejores oportunidades; la otra conclusión que se puede establecer es que un número considerable de voluntarios no tenía experiencia militar, y se movieron por la recesión económica posbélica. Mondolfi (2011, p. 45). 
encontraban 30 menores de edad que según el reglamento electoral, no cumplían con los requisitos para ejercer el sufragio. ${ }^{39}$

Todo parece indicar que el coronel Judas Tadeo Piñango y los oficiales encargados de los comicios en los pueblos del Departamento de San Fernando, interpretaron de manera errónea la normativa electoral, particularmente en lo señalado en el artículo 3 sobre las condiciones que debían cumplir los ciudadanos para participar en estas elecciones primarias. A pesar de que esta irregularidad podía ser causa suficiente para que el general Miguel Guerrero anulara nuevamente el proceso electoral, éste no emitió ningún comentario o crítica sobre el particular, seguramente para no dilatar más la designación de los diputados provinciales o por no considerarlo como un incumplimiento a la normativa comicial. Se recibieron los cuadernos electorales de los pueblos del departamento y con ellos se realizó el conteo final de los electores parroquiales de toda la provincia de Barinas.

Realicemos un balance general de las elecciones parroquiales de la provincia de Barinas: en total participaron 854 ciudadanos -609 militares y 245 civiles- para una proporción de 71\% y 29\% respectivamente. La mayoría de la población civil llanera se dedicaba a las actividades agropecuarias; un importante número de los votantes no sabían escribir su nombre -459 de 854-, firmando los cuadernos electorales con una cruz; mientras que buena parte de la alta jerarquía militar, eclesiásticos y funcionarios públicos, sí rubricaron sus nombres. En el cuadro 1 presento una relación de los ciudadanos que participaron en el proceso electoral, divididos en poblaciones y con algunas características que nos brindaron los cuadernos electorales.

El escrutinio general de las votaciones de los departamentos de la provincia de Barinas se realizó en la población de Achaguas el 31 de octubre de 1820. Aunque el reglamento sólo estipulaba el nombramiento de electores parroquiales principales, las autoridades de la provincia consideraron necesario la selección de electores suplentes "en virtud de que algunos de los que puedan resultar tales, acaso se hallan impedidos de comparecer, bien por enfermedad, bien porque siendo militares ocupan puestos o comisiones de que no pueden

39 Nombramiento de electores parroquiales de San Fernando de Apure, San Fernando de Apure, 23 de octubre de 1820, AGNC, República, Fondo Congreso, leg. 24, rollo 23, f. 120, 121, $124-127,130-138,150-156$. 
Cuadro 1

Relación de los ciudadanos que participaron en el nombramiento de electores parroquiales de la provincia de Barinas

\begin{tabular}{|c|c|c|c|c|c|c|c|c|c|}
\hline Población & Fecha & Votantes & Extranjeros & Civiles & $\begin{array}{l}\text { Casados } \\
\text { (civiles) }\end{array}$ & $\begin{array}{c}\text { Edad } \\
\text { (civiles) }\end{array}$ & Militares & $\begin{array}{l}\text { Casados } \\
\text { (militares) }\end{array}$ & $\begin{array}{c}\text { Edad } \\
\text { (militares) }\end{array}$ \\
\hline Achaguas & 15-30.x.1820 & 173 & 28 & 64 & $42(69 \%)$ & 39 & 109 & $53(48 \%)$ & 31 \\
\hline San Juan de Payara & 16-18.x.1820 & 360 & 3 & 60 & $46(77 \%)$ & 43 & 300 & $102(34 \%)$ & 26 \\
\hline Atamaica/ Cunaviche & 18-21.x.1820 & 42 & 0 & 42 & $33(79 \%)$ & 44 & 0 & 0 & 0 \\
\hline Arichuna & 19.x.1820 & 129 & 6 & 23 & $15(65 \%)$ & 31 & 106 & $35(32 \%)$ & 25 \\
\hline \multicolumn{10}{|l|}{ San Fernando de } \\
\hline \multirow[t]{2}{*}{ Apure } & 23.x.1820 & 150 & 25 & 56 & $33(59 \%)$ & 34 & 94 & $17(18 \%)$ & 26 \\
\hline & Totales & 854 & 62 & 245 & $169(69 \%)$ & 38.8 & 609 & $207(33 \%)$ & 26.7 \\
\hline
\end{tabular}

desprenderse sin ser grave perjuicio de la república." La reflexión del gobernador político, el general Miguel Guerrero sobre el particular es interesante: "pues aunque este acto no esté previsto en el reglamento, no parece extraño ocurrir a él, cuando este es el método conocido en todo género de elecciones" ${ }^{40}$ Seguramente la experiencia de comicios anteriores influyó en esta decisión, especialmente cuando buena parte de los electores principales que fueron seleccionados, eran oficiales de alto rango que tenían importantes responsabilidades en la conducción del Ejército Libertador. Sin menospreciar la política, se le dio prioridad a la dirección de la guerra.

De los quince electores parroquiales principales seleccionados, doce eran militares de alto rango del Ejército Libertador con una amplia experiencia en el campo militar y político, fundamentalmente en las provincias llaneras neogranadinas y venezolanas. Además, y se puede evaluar a partir de los resultados electorales donde concentraron casi el 50\% de las preferencias ciudadanas, gozaban de fama, reputación y admiración entre la población civil y militar de la región, gracias a sus éxitos militares más recientes como había sido la liberación del antiguo virreinato del Nuevo Reino de Granada en agosto de 1819.

$4^{0}$ Escrutinio general para el nombramiento de los electores parroquiales y suplentes de la provincia, Achaguas, 31 de octubre de 1820, AGNC, República, Fondo Congreso, leg. 24, rollo 23, f. 305-305 bis v. 
Más allá de recalcar la figura del general Páez - máxima autoridad política y militar de la región, y seguramente el hombre más fuerte e influyente de Colombia después de Bolívar para ese momento-, entre los electores más votados podemos destacar a los generales Pedro León Torres y Miguel Guerrero, quienes además de tener una sobresaliente carrera militar desde los inicios de la guerra de independencia, poseían experiencia parlamentaria al haber sido diputados al segundo congreso de Venezuela de 1819, el primero como representante de Guayana y el segundo por Barinas. Estos dos oficiales tuvieron una preferencia en el electorado superior al 80\% de los votos emitidos por los ciudadanos de la provincia de Barinas, tanto civiles como militares. ${ }^{41}$

Los civiles más populares fueron el presbítero Trinidad Travieso y los doctores Nicolás Pumar y Ramón Ignacio Méndez, ambos con amplia experiencia parlamentaria. El doctor Pumar recibió gracias a la intermediación del general Páez -de quien era su secretario personal y amigo desde 1816-, el grado de teniente coronel y el empleo de teniente de gobernador, asesor general de la provincia de Barinas y asesor de guerra del ejército del Bajo Apure en 1817; dos años más tarde representó a la Provincia de Barinas en el congreso de 1819. Por su parte, el doctor Méndez había participado en los dos congresos venezolanos como diputado de la misma provincia de Barinas. Recapitulando, es importante reiterar que en su mayoría los electores parroquiales principales que fueron electos, eran oriundos de los llanos venezolanos y pertenecían al círculo más cercano del general José Antonio Páez y en menor medida de los generales Torres y Guerrero.

Como podemos ver en los siguientes cuadros ( 2 y 3), la participación abrumadora de los ciudadanos al servicio de las armas (71\%) favoreció indudablemente la balanza a favor de los oficiales de más alto rango del Ejército Libertador, aunque no podemos despreciar la popularidad de los doctores Pumar y Méndez al ser reconocidos como representantes de la provincia en antiguas

${ }^{41}$ Entre los electores más votados figura el teniente coronel Facundo Mirabal, quien hasta mediados de ese año había militado en el ejército realista donde alcanzó el grado de capitán. A pesar de su anterior cercanía con los oficiales españoles más temidos por los patriotas como José Tomás Boves, José Yáñez y Francisco Tomás Morales, y tener en su haber hasta una victoria sobre el general Páez en 1816, su popularidad entre los llaneros no decayó a pesar de su reciente pasado, y seguramente hasta influenció en la preferencia. 
asambleas legislativas. Así, los quince electores parroquiales principales concentraron poco más del $55 \%$ de las preferencias para un total de votos emitidos de 7 078; en cambio, los electores parroquiales suplentes -fue mayor el número de candidatos- sólo aglutinaron el $23 \%$ de favoritismo para un total de votos emitidos de 2985 .

\section{Cuadro 2}

Votaciones de la provincia de Barinas para el nombramiento de los quince electores parroquiales ${ }^{42}$

\begin{tabular}{lcc}
\hline \multicolumn{1}{c}{ Elector } & Votos & Preferencia \\
\hline Torres, Pedro León (general) & 713 & $83 \%$ \\
\hline Guerrero, Miguel (general) & 695 & $81 \%$ \\
\hline Piñango, Judas Tadeo (coronel) & 600 & $70 \%$ \\
\hline Torres, Francisco (coronel) & 573 & $67 \%$ \\
\hline Páez, José Antonio (general) & 509 & $60 \%$ \\
\hline Briceño, Juan (coronel) & 477 & $56 \%$ \\
\hline Iribarren, Guillermo (coronel) & 472 & $55 \%$ \\
\hline Pumar, Nicolás (doctor) & 463 & $54 \%$ \\
\hline Méndez, Ramón Ignacio (doctor) & 445 & $52 \%$ \\
\hline Palacios, Miguel (teniente coronel) & 383 & $45 \%$ \\
\hline Burgos, Ramón (teniente coronel) & 377 & $44 \%$ \\
\hline Mirabal, Facundo (teniente coronel) & 351 & $41 \%$ \\
\hline Vásquez, Miguel Antonio (coronel) & 346 & $41 \%$ \\
\hline Travieso, Trinidad (presbítero) & 345 & $40 \%$ \\
\hline Cistiaga, Hilario (coronel) & 329 & $39 \%$ \\
\hline Total de votos & 7078 & $55.2 \%$ \\
\hline
\end{tabular}

$4^{2}$ Escrutinio general para el nombramiento de los quince electores parroquiales y suplentes de la provincia, Achaguas, 31 de octubre de 1820, AGNC, República, Fondo Congreso, leg. 24 , rollo 23 , f. 305-305 bis v. 
Cuadro 3

Votaciones de la provincia de Barinas para el nombramiento de los catorce electores parroquiales suplentes ${ }^{43}$

\begin{tabular}{lcc}
\hline \multicolumn{1}{c}{ Elector } & Votos & Preferencia \\
\hline Canelón, Juan & 313 & $37 \%$ \\
\hline Conde, Juan José (mayor) & 305 & $36 \%$ \\
\hline Lamas, Juan (teniente coronel) & 263 & $31 \%$ \\
\hline Días, Asunción & 248 & $29 \%$ \\
\hline Márquez, José María & 241 & $28 \%$ \\
\hline Mujica, Ermenegildo (teniente coronel) & 237 & $28 \%$ \\
\hline Canelón, Miguel (teniente coronel) & 213 & $25 \%$ \\
\hline Mirabal, Juan Antonio (teniente coronel) & 205 & $24 \%$ \\
\hline Pulido, José María (mayor) & 201 & $23 \%$ \\
\hline Pérez, Rafael (teniente coronel) & 164 & $19 \%$ \\
\hline Guerrero, Francisco (teniente coronel) & 154 & $18 \%$ \\
\hline Guerrero, Francisco Antonio & 152 & $18 \%$ \\
\hline Veracierto, Francisco & 150 & $18 \%$ \\
\hline Briceño, Antonio María (presbítero) & 139 & $16 \%$ \\
\hline Total de votos & 2985 & $\%$ \\
\hline
\end{tabular}

\section{Designación de representantes: los colegios electorales de Barinas y Casanare}

El nombramiento de diputados principales y suplentes de la provincia de Casanare se retrasó considerablemente "a causa de lo inundado de los caminos e intransitable de los ríos que no habían permitido la reunión de los electores en el día señalado.” A pesar de los inconvenientes consecuencia de la temporada

${ }^{43}$ En el expediente no queda claro por qué sólo se seleccionaron catorce suplentes. Escrutinio general para el nombramiento de los quince electores parroquiales y suplentes de la provincia, Achaguas, 31 de octubre de 1820, AGNC, República, Fondo Congreso, leg. 24, rollo 23 , f. 305-305 bis v. 
de lluvias de los valles de Casanare, el gobernador de la provincia de Casanare, el coronel Juan José Molina, hizo todo lo posible para reunir lo más rápido a la asamblea de electores parroquiales, instalación que se logró la mañana del 5 de septiembre de $1820 .{ }^{44}$ Sólo se conservó en el Archivo General de la Nación de Colombia una copia del acta de elección de diputados realizadas en la capital de la provincia, no así de las votaciones para la selección de electores parroquiales. La orden para realizar el proceso eleccionario llegó a manos del coronel Juan Nepomuceno Moreno, comandante general de la provincia de Casanare, el 3 de julio. La misma estaba acompañada del n. 44 de la Gazeta de la ciudad de Bogotá, capital del departamento de Cundinamarca, del 28 de mayo de ese año donde se encontraba la convocatoria y reglamento electoral. 45

Los quince electores parroquiales designados por las "asambleas departamentales" de la provincia de Casanare fueron los siguientes: coronel Juan José Molina, los alcaldes José Sebastián Soler y Calixto Molina, el procurador Javier Quintero, el teniente coronel Miguel Peraza, el teniente coronel Francisco Olmedilla, el capitán Mauricio Bejar, el administrador de correos Francisco Javier Cortés, el capitán Javier Cortés, Ignacio Murillo, Florencio Jiménez, José María Ortiz, José Miguel Pérez, José Antonio Gamboa y el inspector de tabaco Felipe Perdomo. ${ }^{46}$

Entre los votantes existió consenso por el nombramiento del general Francisco de Paula Santander (catorce votos), el doctor Salvador Camacho (catorce votos), el general Carlos Soublette (trece votos) y el doctor Vicente Azuero (doce votos) como representantes principales; no así para el quinto diputado, quedando los votos divididos entre los coroneles Bartolomé Salom (tres votos) y

44 Comunicación de Juan José Molina al ministro del interior y justicia relativa al acta de la elección de diputados principales y suplentes practicada en la ciudad de Pore, provincia de Casanare, 5 de septiembre de 1820, AGNC, República, Fondo Ministerio de lo Interior y Relaciones Exteriores, t. 122, rollo 121, f. 5.

45 Juan Nepomuceno Moreno al ministro del interior y justicia, AGNC, República, Fondo Negocios Administrativos, t. 2, rollo 48, f. 769.

${ }^{46}$ Acta de la elección de diputados principales y suplentes de la provincia de Casanare, Pore, 5 de septiembre de 1820, AGNC, República, Fondo Ministerio de lo Interior y Relaciones Exteriores, t. 122 , rollo 121 , f. 6-6 vto. 
Pedro Briceño Méndez (un voto), y el doctor Juan Bautista Estévez (un voto). ${ }^{47}$ Igual caso para los suplentes: el doctor Manuel Baños (quince votos), el doctor Estanislao Vergara (trece votos), el coronel Pedro Briceño Méndez (doce votos) y el doctor Juan Bautista Estévez (once votos); el coronel Salón sería el quinto diputado suplente..$^{8}$ La comunicación fue recibida en Bogotá el 19 de septiembre de 1820.

La representación de la Provincia de Casanare estaba comandada por tres personalidades que tenían fuertes raíces familiares, económicas y políticas con la región a representar, como lo fueron el general Francisco de Paula Santander -vicepresidente del Departamento de Cundinamarca-, y los doctores Salvador Camacho y Vicente Azuero, quienes además fueron colaboradores cercanos de Santander durante estos años y los siguientes. Por mencionar un ejemplo, el abogado Azuero se había desempeñado como miembro de la comisión principal de secuestros en 1819, auditor de guerra de la vicepresidencia del Departamento de Cundinamarca y juez de diezmos en Soatá, una población de Tunja.

Por su parte, regresando a los llanos venezolanos, los resultados de las votaciones fueron enviados al cuartel general de Achaguas donde el general José Antonio Páez certificó el proceso electoral y convocó a la reunión de los quince electores parroquiales para el nombramiento de los diputados principales y suplentes que representarían a la Provincia de Barinas en el congreso colombiano de 1821. Según las órdenes de Páez, ésta se realizaría el mismo día 31 de octubre de 1820, a las 4 de la tarde en su residencia oficial. El único elector que no pudo asistir fue el teniente coronel Juan Ramón Burgos "ya porque se halla enfermo, ya porque no puede desprenderse de la comandancia de la plaza de

47 En el acta no se registró quién de estos tres candidatos quedó como el quinto diputado principal. Sobre el particular, existe una confusión que posiblemente surgió a partir de un error tanto en la Gazeta de la ciudad de Bogotá, capital del departamento de Cundinamarca, n. 71, del 3 de diciembre de 1820 como en el Correo del Orinoco, n. 96 del 17 de febrero de 1821, donde se publicó la lista de diputados del Casanare y se menciona el nombre del doctor Antonio Viana (ministro del tribunal de justicia del Departamento de Cundinamarca) como el quinto diputado principal, candidato que nunca fue mencionado en el acta electoral.

48 Otros candidatos fueron los doctores Ignacio Muñoz, Alejandro Osorio, Francisco Soto, Casimiro Calvo e Ignacio Herrera. Acta de la elección de diputados principales y suplentes de la Provincia de Casanare, Pore, 5 de septiembre de 1820, AGNC, República, Fondo Ministerio de lo Interior y Relaciones Exteriores, t. 122, rollo 121, f. 6-6 vto. 
San Fernando sin un grave perjuicio de la república”. Su lugar lo ocupó el primer suplente, el ciudadano Juan Canelón, un respetado ciudadano mayor de 60 años que había tenido una participación muy activa desde los inicios de la guerra de independencia. En el cuadro 4 muestro los nombres de los diputados principales electos por mayoría absoluta y suplentes electos por mayoría simple. ${ }^{49}$

\section{Cuadro 4}

Diputados principales y suplentes de la Provincia de Barinas al Congreso General de Colombia de $1821^{50}$

\begin{tabular}{ll}
\hline \multicolumn{1}{c}{ Diputados principales } & \multicolumn{1}{c}{ Diputados suplentes } \\
\hline Yanes, Francisco Javier (doctor) & Soto, Francisco \\
\hline Méndez, Ramón Ignacio (presbítero) & Narvarte, Andrés \\
\hline Briceño, Antonio María (presbítero) & Urdaneta, Rafael (general) \\
\hline Pumar, Nicolás (doctor) & Briceño, Juan Nepomuceno (coronel) \\
\hline Briceño Méndez, Pedro (coronel) & Chipía, Agustín (licenciado) \\
\hline
\end{tabular}

Los electores parroquiales -recordemos que once de los quince eran militares-, no privilegiaron precisamente a los oficiales del Ejército Libertador de más alto rango, popularidad o cercanía con los influyentes generales Páez, Torres o Castillo; por el contrario, privilegiaron a los civiles llaneros letrados que tuvieran mayor experiencia en el campo político, particularmente quienes se habían desempeñado como parlamentarios. En síntesis, podríamos considerar que los diputados electos representaron los intereses regionales de una élite política, económica y militar que se había fraguado desde finales del siglo xviı

49 En el expediente no se anexó el escrutinio, sólo la proclamación de los diputados principales y suplentes que obtuvieron la mayoría absoluta y simple, respectivamente. Resultado de las votaciones de los quince electores parroquiales de la Provincia de Barinas para el nombramiento de diputados, Achaguas, 31 de octubre de 1820, AGNC, República, Fondo Congreso, leg. 24 , rollo 23 , f. 305 bis v.-307 V.

${ }^{50}$ Resultado de las votaciones de los quince electores parroquiales de la Provincia de Barinas para el nombramiento de diputados, Achaguas, 31 de octubre de 1820, AGNC, República, Fondo Congreso, leg. 24, rollo 23, f. 305 bis v.-307 v. A manera de ratificación y sin ningún comentario, el nombramiento de diputados principales y suplentes de la Provincia de Barinas se publicó en el Correo del Orinoco del sábado 2 de diciembre de 1820. 
pero, sobre todo, que había tenido que enfrentar una nueva realidad en el escenario de la guerra de independencia.

Por ejemplo, el doctor Francisco Javier Yanes fue representante de Araure (Provincia de Barinas) en el primer congreso de Venezuela de 1811; caso similar al del doctor Ramón Ignacio Méndez quien, además de representar la misma provincia en la asamblea de 1811, se desempeñó como diputado por Barinas en el segundo congreso de Venezuela de 1819, al igual que los también doctores Antonio María Briceño y Nicolás Pumar. El caso del joven coronel Pedro Briceño Méndez guarda especial interés, ya que a pesar de su experiencia en el campo militar, destacó más por sus valores ciudadanos, al grado de ser calificado por Simón Bolívar como un "modelo a los primeros ciudadanos de la República." ${ }^{1}$ Antes de iniciar la guerra de independencia había cursado estudios universitarios en cánones y leyes.

Al concluir el acto de votación ocurrió un episodio singular. El presbítero Ramón Ignacio Méndez, doctor en cánones y en derecho civil egresado de la Universidad de Caracas, pidió la palabra y "expuso al colegio electoral varias razones para exonerarse de la diputación presente”. Destacó en su breve intervención haberse desempeñado "por tres veces consecutivas recargado con este honroso destino" como representante de la Provincia de Barinas en los congresos de 1811, 1819 y 1821. Su principal angustia era "que acaso podría creerse estar ya perpetuado, lo cual chocaría contra los principios que ha adoptado el Pueblo.” En este punto, Méndez cuestionó la reelección de un cargo con estas características y las desventajas que podría ocasionar en la opinión pública. La reunión resolvió no admitir las excusas del elegido, y de esta manera concluyó el acto. ${ }^{2}$

${ }^{51}$ Certificación expedida por Bolívar por la cual hace honrosos elogios al coronel Méndez, Bogotá, 12 de diciembre de 1821, publicado en la Gaceta de Colombia, Bogotá, n. 181, domingo 3 de abril de 1825, p. 4 .

$5^{2}$ El diputado Méndez no sólo fue diputado por Barinas en diferentes períodos, también sería senador en las legislaturas de 1823, 1824, 1825 y 1826. Resultado de las votaciones de los quince electores parroquiales de la Provincia de Barinas para el nombramiento de diputados, Achaguas, 31 de octubre de 1820, AGNC, República, Fondo Congreso, leg. 24, rollo 23, f. 305 bis v.-307 v. 
Realizados los procesos electorales en los territorios neogranadinos y venezolanos entre el 7 de agosto de 1820 y el 6 de octubre de 1821, se reunió el Congreso General de Colombia en fecha posterior a la prevista originalmente. La instalación tuvo lugar el 6 de mayo de 1821 con la asistencia de 57 diputados representantes de las provincias que tuvieron oportunidad de concluir su elección antes de la primera sesión de la asamblea, ya que en realidad se realizaron comicios en 21 provincias. El acontecimiento se celebró con tres días de iluminación, fuegos artificiales, salvas de cañón, misa de acción de gracias y bailes particulares en la noche en diversos rincones de la joven república colombiana. Se reunió durante poco más de cinco meses hasta el 14 de octubre de 1821, para un total de 201 sesiones plenarias. Entre las obras más importantes destaca la aprobación de la Ley Fundamental de los Pueblos de Colombia el 12 de julio de 1821, misma que se proyectó luego a la esencia misma de la Constitución aprobada el 30 de agosto de ese año y promulgada por Simón Bolívar el 6 de octubre de 1821.

\section{Reflexión final}

El principio y la práctica de la representación política como factor de legitimación política ${ }^{53}$ no fue una novedad exclusiva de los territorios que formaron parte de la primera República de Colombia; al contrario, fue un debate que no perdió vigencia a pesar de tener más de una década como materia de discusión en Hispanoamérica. El problema de la representación fue un aspecto clave del complejo proceso que terminó con la desintegración del imperio español y la formación de nuevos estados nacionales en América, todos bajo el amparo de un sistema representativo. Esta problemática puso de manifiesto cuatro elementos a considerar: la definición del sujeto a ser representado; las características de esa representación; los espacios territoriales de ésta (provincias, ciudades y/o pueblos); y la relación entre representado y el representante.

La urgente necesidad de reemplazar la cuestionada legitimidad de la monarquía española en 1810, abrió el camino al establecimiento de un régimen

${ }^{53}$ Sobre la práctica del principio de representación como fundamento de la legitimidad política es fundamental los aportes realizados por Pitkin (1985); Manin (1998). 
representativo sobre cuyas bases debía asentarse la nueva legitimidad política. La idea que imperó en los contemporáneos era establecer un régimen de elección indirecta capaz de ordenar, controlar y disciplinar la participación de la sociedad -civil y militar-, en el caso de Venezuela y el Nuevo Reino de Granada, movilizada como consecuencia de una década de guerra de independencia. Para el asunto en estudio, el gobierno colombiano estableció estrictos criterios para el acceso a la ciudadanía basada en la propiedad, oficio, residencia y matrimonio, valores que tomaron sus élites políticas para la construcción de la nueva república.

La República de Colombia, en sus estructuras constitucionales, políticas, sociales, económicas y culturales, está relacionado con el trabajo realizado por el Congreso General de Colombia reunido en la Villa del Rosario de Cúcuta entre el 6 de mayo y el 14 de octubre de 1821, especialmente en la Ley Fundamental de la Unión de los Pueblo de Colombia y en la Constitución de la República de Colombia.

Los procesos electorales contemplados en su carta magna de 1821 fueron el mecanismo efectivo con que los ciudadanos de la naciente república se manifestaron por medio del voto para elegir a quienes los representarían en las máximas instancias del poder político; innovación, por demás, que modificó de manera significativa la vida política al incorporar las elecciones como elemento de decisión e interacción ciudadana y de renovación del personal político. La representación, la demarcación político-administrativa, junto con la población y, particularmente la ciudadanía, fueron los componentes fundamentales del sistema electoral colombiano en estos difíciles años de convivencia política, pero también de aprendizaje republicano.

En el presente artículo estudié de manera detallada las espinosas condiciones en las cuales se llevó a cabo el proceso electoral en los llanos venezolanos y neogranadinos para el Congreso General de Colombia entre 1820 y 1821. La situación de guerra en este territorio, y la participación de los ciudadanos en armas hicieron de esta elección una excepción para el caso colombiano. Para lograrlo, revisé la diversa composición de los electores y sus elegidos, los resultados de los comicios y los diversos problemas que se suscitaron con el fin de destacar lo que constituyó esta experiencia como parte del proceso mediante el 
cual se dio inicio al establecimiento de un gobierno representativo en la naciente República de Colombia y se buscó progresivamente desmantelar el sistema monárquico imperante.

La labor legislativa representó la consolidación del sistema representativo como recurso legitimador de la nueva república y tuvo una influencia considerable en el establecimiento de los nuevos estados nacionales luego de su disolución en 1830. Estos aspectos han sido desatendidos por la historiografía hispanoamericana, que ha interpretado este largo y complejo ensayo republicano llamado tradicionalmente como la Gran Colombia, como un fracaso, y no como afirmación y consolidación de una república independiente, libre, soberana, popular representativa.

\section{Fuentes}

Archivos

Archivo General de la Nación de Colombia (AGNC). Sección República, Fondo Congreso; Fondo Ministerio de lo Interior y Relaciones Exteriores

Hemerografía

Correo del Orinoco (1818-1821)

Gaceta de Colombia (1821-1831)

Gazeta de la ciudad de Bogotá, capital del departamento de Cundinamarca (1819-1822)

\section{Referencias}

Almarza Villalobos, Á. R. (2007). "Representación en la Provincia de Venezuela. Elecciones para la Junta Suprema Central y Gubernativa del Reino en 
1809”. Anuario de Estudios Bolivarianos (p. 11-40). Caracas: Universidad Simón Bolívar, v. 14.

Almarza Villalobos, Á. R. (2011). "Las primeras Cortes que ha visto América.

Elecciones para el cuerpo conservador de los derechos de Fernando viI en Venezuela (1810-1811)". CONHISREMI, Revista Universitaria de Investigación y Diálogo Académico (p. 77-105) v. 7, n. 3, 2011.

Almarza Villalobos, Á. R. (2012). Por un gobierno representativo. Génesis de la República de Colombia, 1809-1821. Caracas: Fundación Bancaribe y Academia Nacional de la Historia.

ÁviLA, A. (1999). En nombre de la nación: la formación del gobierno representativo en México. México: Editorial Taurus.

Blanco, J. F. y R. Azpurúa (1983). Documentos para la historia de la vida pública del Libertador. Caracas: Ediciones de la Presidencia de la República, 15 t. Boввio, N., N. Matteucci y G. Pasquino (dirs.) (2008). Diccionario de política. México: Siglo xxi, 2 t.

BRown, M. (2010). Aventureros, mercenarios y legiones extranjeras en la independencia de la Gran Colombia. Medellín: La Carreta Editores, Universidad Pedagógica y Tecnológica de Colombia.

Bushnell, D. (1966). El régimen de Santander en la Gran Colombia. Bogotá: Ediciones Tercer Mundo.

CARrera Damas, G. (2010). Colombia, 1821-1827: aprender a edificar una República Moderna. Demolición selectiva de la Monarquía, instauración de la República y reanudación política de la disputa de la independencia. Caracas: Fondo Editorial de Humanidades y Educación de la Universidad Central de Venezuela y Academia Nacional de la Historia.

CAStro Leiva, L. (1985). La Gran Colombia: una ilusión ilustrada. Caracas: Monte Ávila Editores.

GuEdeA, V. (1991). “Los procesos electorales insurgentes”. Estudios de Historia Novohispana, v. 11, p. 201-249.

HÉBRARD, V. (2012). Venezuela independiente. Una nación a través del discurso (1808-1830). Madrid/Frankfurt: Iberoamericana/Vervuert.

IRWIN, D. (2004). "El voto militar en Venezuela: una visión histórica de conjunto”. Latin American Studies Association. Nevada. 
MANin, B. (1998). Los principios del gobierno representativo. Madrid: Alianza Editorial.

Martínez Garnica, A. (2003). "El debate legislativo por las calidades ciudadanas en el régimen representativo del Estado de la Nueva Granada (1821-1853)". Boletín de Historia y Antigüedades, (p. 241-262). Bogotá: Academia Colombiana de Historia.

MarTínez Garnica, A. (2004). "El problema de la representación política en el Primer Congreso del Nuevo Reino de Granada (enero de 1811)". Boletín de Historia y Antigüedades (p. 3-16). Bogotá: Academia Colombiana de Historia.

Martínez Garnica, A. (2007). "La independencia del Nuevo Reino de Granada. Estado de la representación histórica”, en M. Chust y A. Serrano (eds.), Debates sobre las independencias iberoamericanas (p. 201-220). Madrid: Asociación de HIistoriadores Latinoamericanistas Europeos.

Martínez Garnica, A. (2008). La agenda de Colombia, 1819-1831. Bucaramanga: Universidad Industrial de Santander, 2 t.

MezA, R. (2010). La política del trienio liberal español y la independencia de Venezuela 1820-1823. Caracas: Academia Nacional de la Historia.

Mondolfi Gudat, E. (2011). El lado oscuro de una epopeya. Los legionarios británicos en Venezuela. Caracas: Editorial Alfa.

LeAL CuRIEL, C. (2011). "Orígenes del gobierno representativo en Venezuela: el reglamento de J. G. Roscio”. La revolución neogranadina, [en línea: http:// www.revoluciónneogranadina.com] (p. 42-64), n. 1.

Páez, J. A. (1888). Autobiografía del general José Antonio Páez. Caracas: Tipografía de Espinal e Hijos, 2 t.

Pitкin, H. F. (1985). El concepto de representación. Madrid: Centro de Estudios Constitucionales.

Quintero, I. (2006). "Lealtad, soberanía y representación en Hispanoamérica (1808-1811)”, en M. Chust (coord.). Doceañismos, constituciones e independencias. Madrid: Fundación Mapfre.

QuinTERo, I. y Á. R. Almarza Villalobos (2012). "Dos proyectos: un solo territorio. Constitucionalismo, soberanía y representación. Venezuela 1808-1821”, en A. Annino y M. Ternavasio (coords.). El laboratorio constitucional 
iberoamericano: 1807/1808-1830 (p. 55-70). Madrid: Estudios de Historia Latinoamericana, Iberoamericana-Asociación de HIistoriadores Latinoamericanistas Europeos.

Quintero, I. y Á. R. Almarza Villalobos (2015). "Una segunda oportunidad. Representación y revolución en la República de Colombia: 1819-1830”, en R. Altez y M. Chust (eds.). Revoluciones en América Latina. Madrid: Iberoamericana/Vervuert.

Restrepo, J. M. (2009). Historia de la revolución de la República de Colombia en la América Meridional. Medellín: Editorial Universidad de Antioquia, 2 v. Rosanvallon, P. (1999). La consagración del ciudadano. Historia del sufragio universal en Francia. México: Instituto Mora.

Sosa AbelLA, G. (2006). Representación e independencia 1810-1816. Bogotá: Instituto Colombiano de Antropología e Historia.

Ternavasio, M. (2002). La revolución del voto. Política y elecciones en Buenos Aires, 1810-1852. Buenos Aires: Siglo xxI.

ThiBaud, C. (2003). República en armas. Los ejércitos bolivarianos en la guerra de independencia en Colombia y Venezuela. Bogotá: Instituto Francés de Estudios Andinos y Planeta. 